\title{
Faster, cheaper and under control: de-risking CMC development with transposon-derived manufacturing cell lines
}

\author{
Sowmya Rajendran ${ }^{1}$, Sowmya Balasubramanian ${ }^{1}$, Lynn Webster $^{1}$, Maggie Lee ${ }^{1}$, Divya \\ Vavilala $^{1}$, Nicolay Kulikov ${ }^{1}$, Jessica Choi $^{1}$, Calvin Tang ${ }^{1}$, Molly Hunter ${ }^{1}$, Rebecca Wang ${ }^{1}$, \\ Harpreet Kaur ${ }^{1}$, Surya Karunakaran ${ }^{1}$, Varsha Sitaraman ${ }^{1}$, Jeremy Minshull ${ }^{1}$, and Ferenc \\ Boldog ${ }^{1}$
}

${ }^{1}$ ATUM

July 30, 2020

\begin{abstract}
The development of highly productive, genetically stable manufacturing cell lines is on the critical path to IND filing for protein

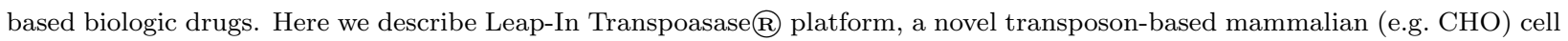
line development system that produces high titer stable pools with productivity and product quality attributes that are highly comparable to clones that are subsequently derived therefrom. The productivity distributions of clones are strongly biased towards high producers and both genetic and expression stability is consistently high. By avoiding the poor integration rates, concatemer formation, detrimental transgene recombination, low average expression level, unpredictable product quality and inconsistent genetic stability characteristic of non-homologous recombination methods, Leap-In provides several opportunities to de-risk programs early and reduce timelines and resources.
\end{abstract}

\section{Hosted file}

CLD Transposon_20200727.pdf available at https://authorea.com/users/347429/articles/473119faster-cheaper-and-under-control-de-risking-cmc-development-with-transposon-derivedmanufacturing-cell-lines

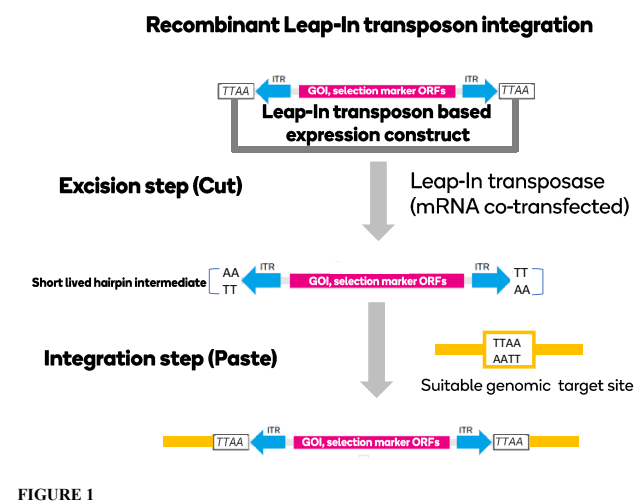

